\title{
Antimicrobial Drug Consumption in Ambulatory Care Settings, Tabuk Region, Saudi Arabia
}

\begin{abstract}
Abeer Hussin Almasoudi, Director, Administration of Research and Studies, Ministry of Health, Tabuk, SAUDI ARABIA. Yousef Ahmed Alomi* iD, The Former General Manager of General Administration of Pharmaceutical Care, Former Head, National Clinical Pharmacy and Pharmacy Practice, Former Head, Pharmacy R\&D Administration, Ministry of Health, Riyadh, SAUDI ARABIA.

Ghormallah Abdullah Alghamdi, Consultant Family Medicine, General Manager of Health Affairs in Tabuk Region, Ministry of Health, Tabuk, SAUDI ARABIA.

\section{Correspondence: \\ Yousef Ahmed Alomi, (Bsc. Pharm, MSc. Clin Pharm, BCPS, BCNSP, DiBA, CDE), The Former General Manager of General Administration of Pharmaceutical Care, Former Head, National Clinical pharmacy and pharmacy practice, Former Head, Pharmacy R\&D Administration, Ministry of Health, Riyadh, SAUDI ARABIA.}

Phone no: +966 504417712

E-mail:yalomi@gmail.com
Received: 02-01-2019;

Accepted: 24-04-2019

Copyright: (c) the author(s),publisher and licensee Pharmacology, Toxicology and Biomedical Reports. This is an open-access article distributed under the terms of the Creative Commons Attribution NonCommercial License, which permits unrestricted non-commercial use, distribution, and reproduction in any medium, provided the original work is properly cited.

This is an open access article distributed under the terms of the Creative Commons Attribution-NonCommercial-ShareAlike 4.0 License

Access this article online

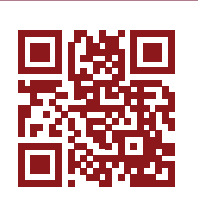

www.ptbreports.org

DOI:

10.5530/PTB.2019.5.18

\begin{abstract}
Objectives: During the $21^{\text {st }}$ century, Antimicrobial Resistance (AMR) has emerged as one of the principal public health problems worldwide. In the coming 20 years, health care systems may be incapable to treat bacterial diseases proficiently due to this miracle. We analyzed data from the North West Region Hospitals, Ministry of Health, Saudi Arabia to determine the level of knowledge regarding drug consumption among patients attending five hospitals in ambulatory care settings. Methods: This cross-sectional study was conducted at North West Region Hospitals in Tabuk city, Saudi Arabia for 9 months. The study contestants were selected from different outpatient departments. National Antimicrobial stewardship program highly demand at our country because of poor insight of antibiotics and misappropriation of antibiotics and poor adherence of antibiotics guidelines. Antibiotic consumption is driven from pharmacy database and calculated based on stranded unit of antimicrobial per each hospital. The total cost expenditure of antimicrobial drug consumption was calculated by Ministry of Health National Cost database. The predictable cost expressed in USD. All data and variables analyzed by Microsoft Excel program version 10. Results: The number of antimicrobial drug consumption in ambulatory care settings in the Saudi Arabia were 25,116 i.e. average 5,023.2 per hospital respectively. The highest drug consumption at all ambulatory care visits were azithromycin tablet $(10,932)$, followed by azithromycin syrup $(7,760)$ and moxifloxacin tablet (3218). The overall antimicrobial consumption was 37,620.12 USD and 7,524.02 USD per each hospital. The overall cost medication consumption were adults ambulatory care departments $69.42 \%(26,114.79$ USD), followed by pediatrics ambulatory care departments $24.52 \%(9,226.018$ USD) and neonates ambulatory care departments $6.06 \%(2,279.32$ USD). The highest medication cost was very broad-spectrum antibiotics like Levofloxacin, Linezolid PO IV and Moxifloxacin PO. It disbursed more than $50 \%$ of the cost burden. Conclusion: Our results exposed a very high obliviousness of antimicrobial drug consumption and its contributing factors among the study contestants. Ambulatory care settings had a high consumption of antimicrobial drugs with burden cost. Thus, health education and responsiveness are highly and instantly suggested to address antimicrobial drug consumption and related resistances in the Tabuk area at ambulatory care settings. Antimicrobial stewardship program at Ambulatory care clinics is necessary to prevent bugs related resistance, improve patient outcome and avoid unnecessary cost on hospitals in Saudi Arabia. Keywords: Antimicrobial, Ambulatory care clinics, Consumption, Hospitals, North West (Tabuk), Saudi Arabia.
\end{abstract}

\section{INTRODUCTION}

Antimicrobial Resistance (AMR) has occurred as one of the most important encounters of public health care and is measured to be one of the primary risks to human health. AMR is defined as the capability of a microorganism to grow or survive despite the presence of adequate level of antibiotics concentration that should be adequate to restrain or kill that organism. With the coming 20 years, health care systems may be unable to manage the bacterial diseases resourcefully. ${ }^{1,2}$ Intensifying factors accountable for the expansion of AMR include poor knowledge, misconceptions, views on infectious diseases, untimely prescription, medication use and patient request. ${ }^{3-5}$

Ambulatory care is part of the health care system provided on an outpatient basis, including diagnosis, opinion, consultation, treatment, intervention and rehabilitation services. Treatment also includes the chronic diseases including the endocrinology, cardiovascular, infectious diseases and dermatology illness with oral therapy. Stable patients can be transferred from emergency services or from inpatient services inside hospitals to continue monitoring patient's management through ambulatory care services. Most of the medications prescribed at ambulatory care units were non-parenteral administration. National antimicrobial stewardship program(AMS) started at the Ministry of Health in 2014 with general common infectious diseases management with empirical antibiotics. ${ }^{6}$ The usage of antimicrobials before and after implementation of the AMS program was assessed. ${ }^{7}$ Several studies showed that the different type of antibiotics consumed at ambulatory care services. ${ }^{8-15}$ Each country had different antibiotics and policy antibiotics prescribing guidelines.

In Saudi Arabia, there is no national surveillance system of antimicrobial drug consumptions. To date, no study has been led in Tabuk (NorthWestern region) to assess the correlations of antibiotics consumption and resistance. Therefore, the results of this study will provide initial data regarding the information about antimicrobial drug consumptions in the Tabuk region. Besides, to best of the author's knowledge, there are no 
studies done about antibiotics consumption at ambulatory care services in the Kingdom of Saudi Arabia or Gulf and Middle East countries.

The aim of the study to explore antibiotics consumption in the Northern region (Tabouk) hospitals in the Kingdom of Saudi Arabia. Therefore, we designed this investigation to explore the level of knowledge regarding drug consumption used by patients visits the ambulatory care setting at most leading hospitals Tabuk regions (Kingdom of Saudi Arabia).

\section{METHODS}

This cross-sectional study was conducted at North West Region Hospitals in Tabuk city, Saudi Arabia, for 9 months. The study contestants were selected from different outpatient departments. All adults, pediatrics and neonatal population were included in this study. The outpatient departments in the five hospitals are the main areas where most of the patients are realized for treatment and follow-up. The data was collected from the five hospitals, which are the leading hospitals in the region of Tabuk. Hospital 1 has been established in 1980, which is containing 100 beds. It provides maternities and pediatrics services. Hospital 2 has been established in 1990 and it contains 100 beds. It provides inpatient, outpatient, narcotics, drug information center, clinics and emergency services. Hospital 3 has been established in 1983, which is containing 100 beds. It provides all specialties except chemotherapeutic services. Hospital 4 has been established in 1991, which is containing 200 beds, which is the largest in the region and served 7 departments. Hospital 5 has been established in 2005, which is the newest and had most of the medical and surgical services. Each hospital had a pharmacy that serves the patients through the different departments. It provides inpatient, outpatient, drug information centers, narcotics and emergency services. Antibiotics committees formulated at all five hospitals through a letter of recommendation had sent by the General Administration of Pharmaceutical Care at the Ministry of Health to the Tabuk Region on October 2013, which instructs the importance of forming a specialized committee on antibiotics under the supervision and follow up of the regional of pharmaceutical care. Letter of formulation of this committee had sent to all hospitals in the Tabuk region in January 2014. In March 2014, this committee was approved by the General Director of Health Affairs in Tabuk Region and guidance to start the application of AMS program in all hospitals in the region, where the actual implementation of the program began in January 2015 . The objective of this antibiotic committees was to improve antimicrobial use for at the hospitals and to diminish the emergence and distribution of antimicrobial resistance. The functions of each committee were supervising the assessment and implementations of antibiotic strategies in hospitals which are designed by the Antibiotics Committee of the Ministry, Saudi Arabia. Preparation of quarterly reports on the implementation of strategies for the use of antibiotics in hospitals reported and discussed with the Committee of Pharmacy and therapeutics in the regions. All the investigated hospitals had a strategic plan to visit hospitals to ensure the accuracy and validity of the implementation of strategies. All the investigated hospitals reviewed and analyzed indicators of the application of strategies for the use of antibiotics and writing the annual report on the performance, growth, productivity and impact of the program in the region of Tabuk. The pharmacy database drives antibiotic consumption and calculated based on the stranded unit of selected antimicrobial per each hospital consumed through ambulatory care setting. The total cost expenditure of antibiotic was calculated by the Ministry of Health National Cost database. The predictable cost expressed in USD. All data and variables analyzed by Microsoft Excel program version 10.

\section{RESULTS}

There were 5 hospitals in this study. The size of hospitals were classified as $100-300$ beds denoted $80 \%$ and $50-99$ beds denoted $20 \%$. All hospitals
(100\%) was accredited by Saudi Board of Hospital Accreditation (CBA$\mathrm{HI}$ ) while none $(0 \%)$ of the hospital accredited by International Joint Commissions. During the study period, the total months response rate for ambulatory care visits were $68(50.37 \%)$ included adults response rate $30(66.66 \%)$, pediatrics response rate $26(57.77 \%)$ and neonates response rate $12(26.66 \%)$ (Table 1$)$. The total number of Antimicrobial standard units at Ambulatory care clinics were $(25,116)$ with average $(5,023.2)$ per hospital. The highest consumption rate for ambulatory care visits were adults $(16,740)$ followed by pediatrics $(6,058)$ and neonates $(1,826)$.

The highest drug consumption was Azithromycin PO $250 \mathrm{mg}$ $64.31 \%(10,765)$ followed by Moxifloxacin PO $400 \mathrm{mg} 17.73 \%(2,968)$ and Levofloxacin IV $500 \mathrm{mg} 8.96 \%(1,500)$ at ambulatory care department of adults. The highest drug consumption was Azithromycin PO $200 \mathrm{mg} / 15$ $\mathrm{mL}(5,957)$ followed by Moxifloxacin PO $400 \mathrm{mg}$ (250) and Azithromycin PO $250 \mathrm{mg}$ (167) at ambulatory care department of pediatrics. The highest drug consumption was Azithromycin PO $200 \mathrm{mg} / 15 \mathrm{~mL}(1,802)$ followed by Meropenem IV $1 \mathrm{~g}(21)$ and Cefepime IV $2 \mathrm{~g}(2)$ at ambulatory care department of neonates. The overall antimicrobial consumption was 37,620.12 USD and 7,524.02 USD per each hospital. The overall cost medication consumption were adults ambulatory care departments $69.42 \%$ (26,114.79 USD), followed by pediatrics ambulatory care departments $24.52 \%$ (9,226.018 USD) and neonates ambulatory care departments $6.06 \%$ (2,279.32 USD). The highest drug cost consumption was Levofloxacin IV $500 \mathrm{mg}$ (12,000 USD) followed by Linezolid PO $600 \mathrm{mg}$ (8,400 USD) and Moxifloxacin PO $400 \mathrm{mg}(3,353.84$ USD) at ambulatory care department of adults. The highest drug cost consumption was Azithromycin PO $200 \mathrm{mg} / 15 \mathrm{~mL}$ (5,658.55 USD) followed by Meropenem IV $500 \mathrm{mg}$ (2,933.7 USD) and Moxifloxacin PO $400 \mathrm{mg}$ (282.5 USD) at ambulatory care department of pediatrics. The highest drug cost consumption was Azithromycin PO $200 \mathrm{mg} / 15 \mathrm{~mL}$ (1,711.72 USD) and Meropenem IV 1g (560.07 USD) at ambulatory care department of neonates. The highest medication cost was very broad-spectrum antibiotics like Levofloxacin, Linezolid PO IV and Moxifloxacin PO. It disbursed more than 50\% of the cost burden (Table 2).

\section{DISCUSSION}

The prime objective of this study was to determine the level of drug consumption among study contestants in five major hospitals in Tabuk city. One of the most important steps in contesting AMR is expanding high antibiotics consumption. Although many methods have been established by healthcare institutions targeting the enhancement in antibiotic use, extreme and unsuitable antibiotic prescribing is still a foremost problem throughout the world. Antimicrobial stewardship programs in hospitals seek to enhance antimicrobial recommending in order to recover individual patient care as well as diminish hospital costs and slow the spread of antimicrobial resistance. These programs emphasis on confirming the proper use of antimicrobials to provide the best patient outcomes, decrease the risk of adverse effects, endorse cost-effectiveness and decrease or steady levels of resistance. Several key performance indicators founded, for instance, the resistance pattern of the antibiotic bugs, adherence to antibiotic prescribing guidelines, adherence to monitoring parameters of some antibiotics need drug levels measurement, monitoring and antibiotics consumption. In this study, we will discover the antimicrobial drug consumption before starting the antibiotics stewardship program in the Northern region in Saudi Arabia. The results derived from five hospitals over a period of nine months. The results should reveal higher consumption number of items within the adult patient with the least consumption of neonatal patient because of more number of quantity and doses used for adults at ambulatory care settings.

The most commonly used antibiotic was Azithromycin or Moxifloxacin for adults at ambulatory care settings because the patient may be suffer- 
Table 1: Hospitals demographic data.

\begin{tabular}{|c|c|c|c|c|c|c|}
\hline & Hospital 1 & Hospital 2 & Hospital 3 & Hospital 4 & Hospital 5 & Total \\
\hline \multicolumn{7}{|l|}{ No of Beds } \\
\hline \multicolumn{7}{|l|}{$<50$} \\
\hline $50-99$ & & & & YES & & $1(20 \%)$ \\
\hline $100-300$ & YES & YES & YES & & YES & $4(80 \%)$ \\
\hline \multicolumn{7}{|l|}{$301-400$} \\
\hline \multicolumn{7}{|l|}{ 401-500 } \\
\hline CIBAHI & Yes & Yes & Yes & Yes & Yes & $5(100 \%)$ \\
\hline JCI & No & No & No & No & No & $0(0 \%)$ \\
\hline \multicolumn{7}{|c|}{ Repose Rate } \\
\hline \multicolumn{7}{|l|}{ ICU units } \\
\hline Adults & 9 & 9 & 4 & 0 & 9 & $31(68.88 \%)$ \\
\hline Pediatrics & 0 & 6 & 4 & 0 & 8 & $18(40) \%)$ \\
\hline Neonates & 2 & 4 & 4 & 0 & 9 & $19(42.22 \%)$ \\
\hline Total & 11 & 19 & 12 & 0 & 26 & $68(50.37 \%)$ \\
\hline \multicolumn{7}{|c|}{ Inpatient wards } \\
\hline Adults & 9 & 9 & 4 & 9 & 9 & $40(88.88 \%)$ \\
\hline Pediatrics & 7 & 9 & 4 & 9 & 9 & $38(84.44 \%)$ \\
\hline Neonates & 3 & 9 & 4 & 9 & 7 & $32(71.11 \%)$ \\
\hline Total & 19 & 27 & 12 & 27 & 25 & $110(81.48 \%)$ \\
\hline \multicolumn{7}{|c|}{ OPD clinics } \\
\hline Adults & 9 & 9 & 4 & 0 & 8 & $30(66.66 \%)$ \\
\hline Pediatrics & 6 & 8 & 4 & 1 & 7 & $26(57.77 \%)$ \\
\hline Neonates & 0 & 8 & 4 & 0 & 0 & $12(26.66 \%)$ \\
\hline Total & 15 & 25 & 12 & 1 & 15 & $68(50.37 \%)$ \\
\hline \multicolumn{7}{|l|}{ ER units } \\
\hline Adults & 9 & 5 & 4 & 0 & 0 & $18(40) \%)$ \\
\hline Pediatrics & 0 & 9 & 4 & 9 & 0 & $22(48.88 \%)$ \\
\hline Neonates & 0 & 5 & 4 & 0 & 0 & $9(20 \%)$ \\
\hline Total & 9 & 19 & 12 & 9 & 0 & $49(36.29 \%)$ \\
\hline
\end{tabular}

ing from chest infection, or pneumonia similar to the previous study in the Quinolones antibiotics consumption only came in next order ${ }^{13}$ and different from New Zealand study of using Penicillin and Tetracycline as first antibiotic consumption. ${ }^{14}$ Antimicrobial use, whether appropriate or inappropriate, helps antimicrobial resistance. Making sure that the increasing use of these agents is clinically appropriate is essential. While most exertions to date endorsing appropriate antibiotic, use have attentive on dipping the use of antimicrobial agents for viral infections, future efforts should be focused towards confirming that when antimicrobial agents are specified, first-line or targeted therapy is active. However, the third medication was used as IV Levofloxacin at ambulatory care settings and it should be used as inpatient services. The most commonly used antibiotic was Azithromycin for pediatric patients, which may be expected due to child infection. Moxifloxacin or IV Levofloxacin was used as second or third, respectively drug consumption at ambulatory care settings. The quinolone antibiotics are not preferable for pediatrics or neonates due to harmful adverse drug reactions. Cumulative rates of consumptions were observed for some of the new, more expensive and broad-spectrum antibiotics, such as azithromycin, amoxicillin/clavulanate, clarithromycin and quinolones. The most drug consumption with neonates was Azithromycin, which may be expected due to bacterial infection. However, the second and third drug consumption was IV meropenem or cefepime, respectively, at ambulatory care settings. The highest cost burden of antibiotics was used at ambulatory care came from adults then pediatrics and neonates due to the high quantity of medications and utilization of costly medications. The cost burden came from the IV Levofloxacin, Linezolid PO IV, Meropenem and Moxifloxacin PO. It disbursed more than $50 \%$ of the cost burden..$^{15}$ The preparation of IV medicines requires the use of an aseptic technique. The consumption of IV is rarely warranted. More investigation is needed to clarify the justification of usage. Increasing antibiotic resistance may harmfully affect the health and cost of care for patients. The antibiotics stewardship program is highly suggested at all hospitals in the northern region in the KSA. ${ }^{16}$

\section{CONCLUSION}

Our results exposed a very high obliviousness of antimicrobial drug consumption and its contributing factors among the study contestants. Ambulatory care settings had a high consumption of antimicrobial drugs with burden cost. Thus, health education and responsiveness are highly and instantly suggested to address antimicrobial usage in the Tabuk area 
Table 2: Anti-Microbial drugs consumption at Ambulatory care departments.

\begin{tabular}{|c|c|c|c|c|c|c|c|c|c|}
\hline $\begin{array}{c}\text { Quantity consumption Anti-infectious } \\
\text { drugs }\end{array}$ & Dosage Forms & Neonates & $\begin{array}{l}\text { cost } \\
\text { (USD) }\end{array}$ & Pediatrics & $\begin{array}{l}\text { cost } \\
\text { (USD) }\end{array}$ & Adults & $\begin{array}{l}\text { cost } \\
\text { (USD) }\end{array}$ & $\begin{array}{c}\text { Total } \\
\text { Quantities }\end{array}$ & $\begin{array}{l}\text { Total cost } \\
\text { (USD) }\end{array}$ \\
\hline Cloxacillin sodium IV 250mg & Vial or amp. & 0 & 0 & 0 & 0 & & 0 & 0 & 0.00 \\
\hline Flucloxacillin sodium IV 250mg & Vial or amp. & 0 & 0 & 0 & 0 & 0 & 0 & 0 & 0.00 \\
\hline Piperacillin + Tazobactam IV $2.25 \mathrm{~g}$ & Vial & 0 & 0 & 0 & 0 & 0 & 0 & 0 & 0.00 \\
\hline Piperacillin + Tazobactam IV $4.5 \mathrm{~g}$ & Vial & 0 & 0 & 0 & 0 & 0 & 0 & 0 & 0.00 \\
\hline Ceftazidime IV $1 \mathrm{~g}$ & Vial & 0 & 0 & 0 & 0 & 34 & 25.3878 & 34 & 25.39 \\
\hline Ceftriaxone IV $1 \mathrm{~g}$ & Vial & 0 & 0 & 26 & 19.24 & 124 & 91.76 & 150 & 111.00 \\
\hline Cefepime IV $1 \mathrm{~g}$ & Vial & 0 & 0 & 0 & 0 & 0 & 0 & 0 & 0.00 \\
\hline Cefepime IV $2 \mathrm{~g}$ & Vial & 2 & 6.9334 & 0 & 0 & 0 & 0 & 2 & 6.93 \\
\hline Imipenem + Cilastatin IV 500mg+500mg & Vial & 0 & 0 & 0 & 0 & 0 & 0 & 0 & 0.00 \\
\hline Meropenem IV 500mg & Vial & 0 & 0 & 0 & 0 & 85 & 1156 & 85 & $1,156.00$ \\
\hline Meropenem IV $1 \mathrm{~g}$ & Vial & 21 & 560.07 & 110 & 2933.7 & 0 & 0 & 131 & $3,493.77$ \\
\hline Tigecycline IV 50mg & Vial & 0 & 0 & 0 & 0 & 0 & 0 & 0 & 0.00 \\
\hline Amikacin IV 100mg & Vial or amp. & 0 & 0 & 0 & 0 & 0 & 0 & 0 & 0.00 \\
\hline Amikacin IV 500mg & Vial or amp. & 0 & 0 & 0 & 0 & 182 & 81.9 & 182 & 81.90 \\
\hline Gentamicin IV 20mg & Vial or amp. & 1 & 0.6 & 0 & 0 & 0 & 0 & 1 & 0.60 \\
\hline Gentamicin IV 80mg & Vial or amp. & 0 & 0 & 0 & 0 & 0 & 0 & 0 & 0.00 \\
\hline Azithromycin PO 250mg & Tablet & 0 & 0 & 167 & 12.024 & 10765 & 775.08 & 10932 & 787.10 \\
\hline Azithromycin PO 200mg/15ml & Suspension & 1802 & 1711.72 & 5957 & 5658.554 & 1 & 0.9499 & 7760 & $7,371.22$ \\
\hline Clindamycin IV 300mg & Ampoule & 0 & 0 & 0 & 0 & 0 & 0 & 0 & 0.00 \\
\hline Vancomycin IV 500mg & Vial & 0 & 0 & 0 & 0 & 35 & 47.25 & 35 & 47.25 \\
\hline Linezolid PO 600mg & Tablet & 0 & 0 & 0 & 0 & 120 & 8400 & 120 & $8,400.00$ \\
\hline Linezolid IV 600mg & Premixed bag & 0 & 0 & 0 & 0 & 0 & 0 & 0 & 0.00 \\
\hline Linezolid PO 100mg & Suspension & 0 & 0 & 0 & 0 & & 0 & 0 & 0.00 \\
\hline Rifabutine PO 150mg & Tablet & 0 & 0 & 0 & 0 & 850 & 74.8 & 850 & 74.80 \\
\hline Ciprofloxacin IV 200mg & Bottle & 0 & 0 & 0 & 0 & 16 & 11.824 & 16 & 11.82 \\
\hline Moxifloxacin IV 400mg & Vial & 0 & 0 & 0 & 0 & 0 & 0 & 0 & 0.00 \\
\hline Moxifloxacin PO 400mg & Tablet & 0 & 0 & 250 & 282.5 & 2968 & 3353.84 & 3218 & $3,636.34$ \\
\hline Levofloxacin IV 500mg & Premixed bag & 0 & 0 & 40 & 320 & 1500 & 12000 & 1540 & $12,320.00$ \\
\hline Amphotericin B liposomal 50mg & Vial & 0 & 0 & 0 & 0 & 0 & 0 & 0 & 0.00 \\
\hline Amphotericin B 50mg & Vial & 0 & 0 & 0 & 0 & 0 & 0 & 0 & 0.00 \\
\hline Voriconazole IV 200mg & Vial & 0 & 0 & 0 & 0 & 0 & 0 & 0 & 0.00 \\
\hline Voriconazole PO 200mg & Tablet & 0 & 0 & 0 & 0 & 0 & 0 & 0 & 0.00 \\
\hline Caspofungin IV 50mg & Vial & 0 & 0 & 0 & 0 & 0 & 0 & 0 & 0.00 \\
\hline Micafungin IV 50 mg & Vial & 0 & 0 & 0 & 0 & 0 & 0 & 0 & 0.00 \\
\hline Acyclovir IV 250mg & Vial & 0 & 0 & 0 & 0 & 60 & 96 & 60 & 96.00 \\
\hline Valaciclovir PO 500mg & Tablet & 0 & 0 & 0 & 0 & 0 & 0 & 0 & 0.00 \\
\hline Artemisinin PO 250mg & Capsule & 0 & 0 & 0 & 0 & 0 & 0 & 0 & 0.00 \\
\hline Artesunate PO 50mg & Tablet & 0 & 0 & 0 & 0 & 0 & 0 & 0 & 0.00 \\
\hline Artesunate IV 60mg & Ampoule & 0 & 0 & 0 & 0 & 0 & 0 & 0 & 0.00 \\
\hline Proguanil PO 100mg & Tablet & 0 & 0 & 0 & 0 & 0 & 0 & 0 & 0.00 \\
\hline Artemether +Lumefantrine PO 20/120mg & Tablet & 0 & 0 & 0 & 0 & 0 & 0 & 0 & 0.00 \\
\hline \multirow[t]{2}{*}{ Artmether IV 20mg } & Ampoule & 0 & 0 & 0 & 0 & 0 & 0 & 0 & 0.00 \\
\hline & & 1,826 & 2279.323 & 6,058 & $9,226.018$ & 16,740 & 26114.79 & 25,116 & $37,620.12$ \\
\hline
\end{tabular}


at ambulatory care settings. In addition, the healthcare providers including pharmacist in all hospitals must also play a role in providing information to their patients so that they can assume positive actions regarding the careful use of antibiotics. The antibiotic stewardship program at ambulatory care services is highly recommended in the district. Further studies are demanding to follow up on the annual antibiotics utilization in the ambulatory care practice.

\section{ACKNOWLEDGEMENT}

None.

\section{CONFLICT OF INTEREST}

The authors declare that there are no conflicts of interest.

\section{ABBREVIATIONS}

AMR: Antimicrobial resistance; AMS: National antimicrobial stewardship program; UDS: Unite State Dollars; CBAHI: Saudi Board of Hospital Accreditation; MOH: Ministry of Health; KSA: Kingdom of Saudi Arabia.

\section{ORCID ID}

Yousef Ahmed Alomi iD https://orcid.org/0000-0003-1381-628X

\section{REFERENCES}

1. Viens A, Littmann J. Is antimicrobial resistance a slowly emerging disaster? Public Health Ethics. 2015;8(3):255-65.

2. Hwang AY, Gums JG. The emergence and evolution of antimicrobial resistance: Impact on a global scale. Bioorg Med Chem. 2016;24(24):6440-5.

3. Grigoryan L, Burgerhof JG, Degener JE, et al. Attitudes, beliefs and knowledge concerning antibiotic use and self-medication: A comparative European study.
Pharmacoepidemiol Drug Saf. 2007;16(11):1234-43.

4. André M, Vernby A, Berg J, Lundborg CS. A survey of public knowledge and awareness related to antibiotic use and resistance in Sweden. J Antimicrob Chemother. 2010;65(6):1292-6.

5. Harbarth S, Samore MH. Antimicrobial resistance determinants and future control. Emerg Infect Dis. 2005;11(6):794.

6. AlomiYA National Antimicrobial Stewardship Program in Saudi Arabia: Initiative and the Future. Open Access J Surg. 2017;4(5):1-7.

7. Lee CF, Cowling BJ, Feng $\mathrm{S}$, Aso H, Wu P, Fukuda K, et al. Impact of antibiotic stewardship programmes in Asia: A systematic review and meta-analysis. $J$ Antimicrob Chemother. 2018;73(4):844-51.

8. Bin AAA, Altannir MA, Almansor MA, Almohaya MS, Onazi AS, Marei MA et al. Non prescribed sale of antibiotics in Riyadh, Saudi Arabia: A cross sectional study. BMC Public Health. 2011;11:538.

9. Al-Niemat SI, Aljbouri TM, Goussous LS, Efaishat RA, Salah RK. Antibiotic prescribing patterns in outpatient emergency clinics at Queen Rania Al Abdullah II Children's Hospital, Jordan, 2013. Oman Med J. 2014;29(4):250-4.

10. European Centre for Disease Prevention and Control. Antimicrobial consumption 2016. Annual epidemiological report for 2016. 2018. Available from: https://ecdo europa.eu/sites/portal/files/documents/AER_for_2016-AMC.pdf

11. Adriaenssens N, Coenen S, Versporten A, Muller A, Minalu G, Faes C, et al. European Surveillance of Antimicrobial Consumption (ESAC): Outpatient antibiotic use in Europe (1997-2009). J Antimicrob Chemother. 2011;66(Suppl 6):3-12.

12. Bin NS, Nafesa SB, Alamery AH, Alhumaid MA, AlMuhaidib HM, Al-Eidan FA Over-the-counter antibiotics in Saudi Arabia, an urgent call for policy makers. J Infect Public Health. 2017;10(5):522-6.

13. Oqal MKA, Elmorsy SA, Alfhmy AK, Alhadhrami RM, Ekram RA, Althobaiti IA, et al. Patterns of antibiotic prescriptions in the outpatient department and emergency room at a Tertiary Care Center in Saudi Arabia. Saudi J Med Med Sci. 2015;3(2):124-9

14. Williamson DA, Roos R, Verrall A, Smith A, Thomas MG. Trends, demographics and disparities in outpatient antibiotic consumption in New Zealand: A national study. J Antimicrob Chemother. 2016:71(12):3593-8.

15. Al-Jumaili AA, Hussein AH, Al-Rekabi MD, Raheem SA, Ernst EJ. Antimicrobial utilization in an Iraqi province: A comprehensive evaluation of antibiotic source and cost. Int J Pharm Pract. 2017:25(1):81-8

16. Enani MA. The antimicrobial stewardship program in Gulf Cooperation Council (GCC) states: Insights from a regional survey. J Infect Prev. 2016;17(1):16-20. 